\title{
An unusually severe case of the cast syndrome
}

\author{
R. H. KENNEDY \\ F.R.C.S.
}

\author{
M. J. COOPER \\ M.S., F.R.C.S.
}

Bristol Royal Infirmary, Bristol BS2 $8 \mathrm{HW}$

\begin{abstract}
Summary
A severe case of the cast syndrome is described following Harrington rod distraction and application of a body cast. The case was unusual as it presented late with no warning symptoms and progressed rapidly to death.
\end{abstract}

KEY WORDS: superior mesenteric artery syndrome, stomach perforation, subcutaneous emphysema, scoliosis.

\section{Introduction}

Correction of a scoliosis by application of a plaster jacket or spinal distraction may lead to duodenal compression by the superior mesenteric artery (Dorph, 1950; Berk and Coulson, 1970; Bunch and Delaney, 1970; Evarts, Winter and Hall, 1971). The following case is unusual as it presented late without warning symptoms.

\section{Case report}

A 14-year-old mentally retarded boy of thin build had a spinal fusion for treatment of a thoracic scoliosis after 14 months in a Milwaukee brace. Correction of a right lateral scoliosis from $73^{\circ}$ to $54^{\circ}$ was achieved by Harrington rod distraction, a plaster jacket being applied to protect the spine further. He was eating normally by the third postoperative day and was discharged on the 10th day, fit and well. During the following month, he was closely supervised and remained well, taking a normal diet without vomiting.

Forty days postoperation, he vomited once and collapsed. Removal of the plaster jacket on admission revealed a tense tympanitic abdomen, with surgical emphysema of the abdominal wall, scrotum and thighs. Circulatory collapse (heart rate $100 / \mathrm{min}$; blood pressure $70 / 30 \mathrm{mmHg}$ ) was associated with marked peripheral cyanosis. Plain abdominal X-ray (Fig. 1) demonstrated a stomach grossly distended with food and free intra-abdominal gas.

Laparotomy released a high pressure pneumoperitoneum and revealed a generalized peritonitis with

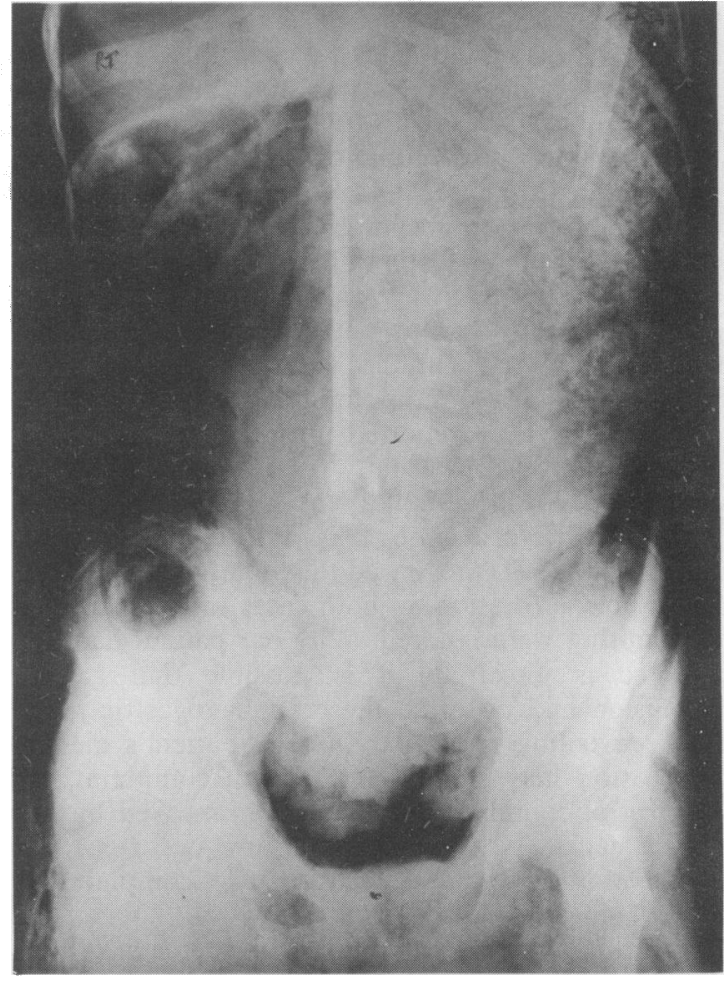

FIG. 1. Plain abdominal X-ray showing spine with Harrington distraction rod in place. There is free intra-abdominal gas and the stomach is grossly distended with food. Subcutaneous emphysema can be seen over the thighs.

free gastric contents. The stomach was distended and gangrenous with a large perforation in the fundus. The proximal duodenum was dilated; the remaining small intestine was collapsed and cyanosed with gas bubbles present in the mesenteric veins. A total gastrectomy was performed with an oesophagojejunal anastomosis. Cardiac arrest occurred $30 \mathrm{~min}$ later and resuscitation was unsuccessful.

At autopsy, the proximal duodenum was dilated 
(16 $\mathrm{cm}$ circumference), narrowing as it passed through the angle between the superior mesenteric artery and the aorta to $8 \mathrm{~cm}$ circumference. The resected stomach was grossly dilated; histology revealed mucosal damage throughout with full thickness infarction of the stomach wall in many areas.

\section{Discussion}

Gastric distension secondary to vascular compression of the duodenum results from narrowing of the angle between the superior mesenteric artery and the aorta (Skandalakis et al., 1977). This occurs in response to spinal distraction or body cast application; both these factors are present in the case described. A similar picture may be seen after massive weight loss removes the fat pad in the mesenteric root (Wayne, Miller and Eisman, 1971).

The sudden and dramatic late presentation is uncommon as nausea and vomiting usually occur early; failure to appreciate the significance of these warning symptoms leads to hypovolaemia, alkalosis and eventually death (Warner et al., 1974; Lundell and Thulin, 1980), Our patient had made an uneventful recovery with no vomiting, and with no weight loss to explain the timing of the presentation.

Death has been reported in association with the 'cast syndrome' and usually results from inhalation of vomitus or occasionally as a result of gastric perforation (Evarts et al., 1971; Warner et al., 1974). Evarts et al. (1971) reviewed the literature and found 2 cases of perforation, in both cases early symptoms of vomiting were ignored. Why our patient had not vomited is uncertain, it is possible that gastric distension had distorted the oesophagogastric junction preventing regurgitation. The patient's mental retardation may explain his lack of complaint, all signs of abdominal distension being masked by the plaster jacket. Once gastric rupture occurred, the course was rapid, the time from first complaint to death being only $6 \mathrm{hr}$.

A similar case was reported by Warner et al. (1974) who postulated that gastric perforation was the result of coeliac axis compression; no evidence for this was found at operation or post mortem examination:
Laparotomy on our patient released a high pressufe pneumoperitoneum and it is more probable the gastric distension led to pressure necrosis of the stomach wall. The origin of the gas is uncertain butt fermentation may have been occurring in the gastriac contents.

The presence of gas bubbles in the mesente傜 veins is a finding of ominous significance; it is usual原 seen in the presence of necrotic bowel and $\mathrm{as}$ associated with a $75 \%$ mortality (Liebman et af, 1978). Subcutaneous emphysema is minimal in the absence of thoracic pathology, but has been reported after gastro-intestinal perforation (Iancu. El-Drör and Kahn, 1972; Nowak and Tomlanovich, 1977). presence over the lower abdominal wall and scrotum is more common after perforations of the anus ante rectum than after gastric rupture (Nowak and Torb. lanovich, 1977).

\section{References}

BERK, R.N. \& Coulson, D.B. (1970) The body cast syndrome. Radiology, 94, 303.

BUNCH, W. \& Delaney, J. (1970) Scoliosis and acute vascular compression of the duodenum. Surgery, 67, 901.

DoRPH, M.H. (1950) The cast syndrome. Review of the literature and report of a case. New England Journal of Medicine, 243, 4 40.

EVARTS, C.M., WiNTER, R.B. \& HALL, J.E. (1971) Vascular compression of the duodenum associated with the treatmegt $\frac{\mathrm{g}^{f}}{\mathrm{~g}}$ scoliosis. Journal of Bone and Joint Surgery, 53A, 431.

IANCU, T., EL-DROR, Y. \& KAHN, M. (1972) Neonatal gastffC rupture presenting with subcutaneous emphysema. Jour Pediatric Surgery, 7, 68.

Liebman, P.R., Patten, M.T., Benfield, J.R. \& Hechtman, H (1978) Hepatic-portal venous gas in adults: etiology, pathophysi. logy and clinical significance. Annals of Surgery, 187, 281.

LUNDELL, L. \& THULIN, A. (1980) Wilkie's syndrome-a rariß? British Journal of Surgery, 67, 604.

NowAK, R.M. \& ToMLANOVICH, M.C. (1977) Subcutaneous emple sema. Journal of the American College of Emergency Physiciass and the University Association for Emergency Medical Services, 269.

Skandalakis, J.E., AKIN, J.T., MilsaP, J.H. \& Gray, S.W. (1977) Vascular compression of the duodenum, Part 2. Contempor $y$ Surgery, 10, 33

WARNER, T.F.C.S., SHORTER, R.G., MCllRATH, D.C. \& DUPRE, E.L. (1974) The cast syndrome. An unusually severe case. Jour of Bone and Joint Surgery, 56A, 1263.

WAYNe, E., MILleR, R.E. \& EISMAN, B. (1971) Duodenal obstrif tion by the superior mesenteric artery in bedridden combat casualties. Annals of Surgery, 174, 339.

(Accepted 7 December 1982) 